\title{
Memorias de la violencia política en la narrativa de jóvenes escolares del sur del departamento de Casanare
}

Memories of Political Violence in Narratives Made by School Students from the South of the Casanare Department

Memórias da violência política na narrativa de jovens escolares no sul do departamento de Casanare

\section{Miller Antonio Pérez Lasprilla* (iD orcid.org/0000-0001-5855-5971}

\section{Artículo de investigación}

Revista Colombiana de Educación, N.ำ 7 . Segundo semestre de 2016, Bogotá, Colombia.

Para citar: Pérez, M. A. (2016). Memorias de la violencia política en la narrativa de jóvenes escolares del sur del departamento de Casanare. Revista Colombiana de Educación, (71), 361-382. 


\section{Resumen}

El presente texto presenta los resultados de la investigación Memorias de la violencia política en la narrativa de jóvenes escolares del sur del departamento de Casanare**.

El ejercicio plantea una interpretación de las formaciones de la subjetividad ética y política de un grupo de jóvenes del sur del Departamento de Casanare, a partir de la memoria narrativa de una serie de acontecimientos violentos que tuvieron lugar en la zona durante el año 2003 y el primer semestre del año 2004.

Para este efecto, se realiza un análisis de memorias a partir de principios teóricos y metodológicos asociados a la fenomenología, la hermenéutica y la teoría narrativa de constitución y construcción del sí mismo, en el marco de referencias sobre las formaciones de la subjetividad en contextos de violencia política en Colombia.

\section{Keywords}

memory; ethical and political education; subjectivity

\begin{abstract}
This paper presents the results of a research called Memories of Political Violence in Narratives by School Students in the South of the Casanare Department.

This paper is an interpretation of the ethic and political subjectivity construction of a group of teenagers in the south of the Casanare department. This was done through the narrative memory of a series of violent events which took place in this area during 2003 and early 2004

In order to do so, the teenagers' memories were analyzed based on theoretical and methodological principles associated to phenomenological principles associated to phenomenology, hermeneutics and the narrative theory of constitution and self-construction. The study was carried out on the grounds of subjectivity formation in political violence contexts in Colombia.
\end{abstract}

\section{Resumo}

Este artigo apresenta os resultados de relatórios de violência política na narrativa de crianças em idade escolar no departamento sul de Casanare. O exercício é uma interpretação das formaçōes da subjetividade de um grupo de jovens do Sul Departamento de Casanare, a partir da memória narrativa de uma série de eventos violentos que ocorreram na área em 2003 e no primeiro semestre de 2004.

Para este efeito, é feita uma análise de memórias de princípios teóricos e metodológicos relacionados com a fenomenologia hermenêutica ea teoria narrativa e construção da própria Constituição, no quadro de referências para as formações de subjetividade em contextos de violência política na Colômbia.

\section{Palavras chave}

memória; ética e educação política; subjetividade

N..$^{\circ} 71$ 


\section{Introducción}

I a historia de la violencia en Colombia incluye diferentes capítulos y formas de comprender su emergencia, sostenimiento y transformación. En la mayoría de los análisis disponibles se cuenta la guerra de la independencia, la violencia partidista, la guerra contra el narcotráfico, la confrontación entre las guerrillas, el Estado y los grupos paramilitares, las cuales han sido comprendidas a través de teorías autorreferentes y naturalistas (Amaya, 2000) o de desigualdad y exclusión (Deas, 1995).

Esas interpretaciones y delimitaciones han venido aportando sentidos asociados a una cierta determinación de la violencia en la historia social y política de los colombianos (Pécaut, 2000), junto con profecías de autocumplimiento (Castillejo, 2000) que intentan explicar el mantenimiento de la violencia en un ciclo permanente de actualización, en el que solo cambian las circunstancias, los actores y las víctimas sin que se observe una alternativa clara de convivencia pacífica.

En este marco, estos y otros análisis sobre el sentido y la configuración sociohistórica de la violencia en Colombia han permitido comprender que la violencia política ha venido incidiendo en la forma particular en que la mayoría de colombianos se comprenden y comprenden a los demás en un amplio marco social de relación, dado su carácter sistemático y prolongado en la historia del país.

Sin embargo, la mayoría de estos análisis se han venido realizando desde perspectivas históricas centradas en la voz de los líderes y estadísticas de muertos y desaparecidos, lo que revela los acontecimientos pero al margen de la experiencia de las víctimas de los hechos violentos.

Como alternativa a este enfoque, en los últimos años ha venido cobrando fuerza la perspectiva de la nueva historia, que cuenta los acontecimientos "desde abajo" (Burke, 2003) y da un mayor protagonismo a la memoria narrativa. Esta, a diferencia del enfoque tradicional de la historia, como ciencia que busca ofrecer datos objetivos sobre los acontecimientos, constituye las construcciones subjetivas, situadas culturalmente de versiones del pasado que comportan formas particulares de ubicarse frente a realidades abrumadoras como la violencia política. Para Todorov (2012), la memoria puede entenderse como

la expresión verbal de una experiencia subjetiva, ya sea individual o colectiva. El individuo-sujeto ha vivido el mismo un hecho y restituye sus recuerdos. El otro término "historia" no corresponde a una visión objetiva del mismo hecho -un proyecto irrealizable--, sino más bien a una reconstrucción intersubjetiva (p. 7).

Esta perspectiva ha ganado protagonismo a partir de las investigaciones sobre las experiencias de violencia política en la historia reciente de la 
humanidad, a cargo de autores como Primo Leví (1989) y Hannah Arendt (2004), quienes destacan la importancia de recuperar las memorias de las víctimas de hechos atroces para evitar la victimización permanente que provoca el silencio. Estos autores mencionan que la oportunidad de elaborar la memoria de los hechos violentos moviliza construcciones sociales de apoyo colectivo, y con ello, se anima la construcción de lazos sociales que con el tiempo pueden evitar que los hechos violentos se repitan.

\section{Memoria, violencia política y formación de la subjetividad}

Se ha venido apelando al trabajo de Paul Ricoeur (1995, 1997, 1999, 2003, y 2004) para vincular la dimensión narrativa de la memoria en el ámbito político, lo cual representa la forma en que los sujetos se organizan para vivir juntos (Arendt, 1997). La narrativa, afirma Ricoeur, es la única vía de expresión de la memoria, puesto que el fenómeno mnemónico requiere del lenguaje para darles sentido a los hechos del pasado, y a la vez, el sentido que produce la narrativa se articula desde una manera de entender la forma de vivir con los Otros. Así, memoria, narrativa y política guardan una relación intrínseca que exige asomarse a los modos de producción de sentido en aspectos como las formaciones de la subjetividad frente a fenómenos disruptivos de violencia.

El principio de la memoria narrativa de Ricoeur deviene de la tradición que se opone al cogito ergo sum de Descartes, en la cual el sujeto está constituido como esencia que se trasciende a sí misma a través de la duda. Como alude Moya, esta perspectiva "tiende a caracterizarse en términos de la conciencia inmediata que un sujeto tiene, en la perspectiva de la primera persona, de entidades y eventos no físicos que pueblan su mente" (1996, p. 159).

Luego de las críticas a esta forma de entender al sujeto por filósofos como Nietzsche (2005), se empezó a fortalecer la idea de que el lenguaje tiene un papel fundamental en la formación de la subjetividad y la idea de sí mismo que construimos con base en la experiencia de vida.

De acuerdo a esta perspectiva, la experiencia sitúa al sujeto en un entorno social con unos otros. En este sentido, ya no se trata de un sujeto que reflexiona consigo mismo en un marco formal de pensamiento. Por el contrario, el sujeto se constituye a partir de experiencias dadas por las tradiciones y avanza en la significación del mundo relacionándose con los otros en un marco histórico y social determinado.

En esta línea de pensamiento, Ricoeur propone la teoría narrativa como el proceso de constitución del sí mismo. Asegura que de esta forma el lenguaje puede entenderse más allá del plano descriptivo al prescriptivo; uno que configura una forma de entenderse y entender a los demás. Porque desde esta perspectiva, las acciones que se organizan en un relato se 
articulan en el ámbito de una ética; es decir, de una forma de entender las relaciones con los Otros a través de las atribuciones de sentido con las cuales se sitúa uno y otro sujeto frente a las acciones del pasado, la reflexión del presente y la proyección del futuro. De esta forma, el relato constituye una trama ${ }^{1}$, una estructura que configura una forma de entender al Otro.

Esta consideración sobre la ética implícita en el acto de narrar es lo que Ricoeur denomina ética narrativa, aquella que aparece implícita en la forma como entiendo a los demás en las narraciones que necesariamente los incluyen, puesto que no puedo decir algo de mí sin referirme a los Otros.

Dicho de otra forma, la teoría narrativa solo sirve verdaderamente de mediación entre la descripción y la prescripción si la ampliación del campo práctico y la anticipación de consideraciones éticas están implicadas en la estructura misma del acto de narrar (Ricoeur, 2003, p. 109).

Esta forma de entender la ética corresponde a la comprensión del ser en el mundo que Ricoeur toma de Heidegger (1951) para definir un campo práctico en la búsqueda de condiciones justas en el marco de los derechos de cada uno.

Con estos elementos, el debate sobre las formaciones de la subjetividad ha venido vinculando la memoria narrativa y la violencia política como polos de producción de sentido en contextos de guerra y confrontación a través del concepto de acontecimiento que irrumpe y trastoca el orden social que acoge a los sujetos sociales. La violencia entra en la vida de los sujetos y es la partera de su historia común, y la memoria narrativa es el medio de formación del sí mismo como apropiación subjetiva del mundo.

El acontecimiento narrativo es definido por su relación con la operación misma de la configuración; participa de la estructura inestable de la concordancia discordante característica de la propia trama; es fuente de discordancia, en cuanto que surge, y fuente de concordancia en cuanto hace avanzar la historia (Ricoeur, 2003, p. 140).

Además, si entendemos que "la formación [...] refiere las interacciones sujeto-mundo en que mutuamente se afectan y transforman" (Vargas, 2007 , p. 37), se puede comprender que la memoria y su correlato, la narración, constituyen la única posibilidad de relación entre el sujeto y el mundo que lo rodea, y es tanto posibilidad de relación como de apropiación y perspectivas de cambio y transformación. Porque como dice Zemelman (1996) "Toda práctica social conecta pasado y futuro en su concreción presente, ya que siempre se mostrará una doble subjetividad:

1 Sobre la trama narrativa, Ricoeur (2003) menciona que "La caracterizamos, en términos dinámicos, por la concurrencia entre una exigencia de concordancia y la admisión de discordancias que, hasta el cierre del relato, ponen en peligro esta identidad" (p. 139). 
como reconstrucción de pasado (memoria) y como apropiación del futuro, dependiendo la constitución del sujeto de articulación de ambas" (p. 116).

De otro modo,

se dice, [la política] es una necesidad ineludible para la vida humana, tanto individual como social. Puesto que el hombre no es autárquico, sino que depende en su existencia de otros, el cuidado de esta debe concernir a todos, sin lo cual la convivencia sería imposible (Arendt, 1997, p. 58).

Allí donde los hombres conviven hay y ha habido política, porque según la definición aristotélica, el hombre es un animal político y necesita contar con los otros para poder vivir. Cuando el sujeto irrumpe en el mundo como un extranjero, encuentra un contexto social hecho de tradiciones, cultura, formas de organización política, y a partir de ahí, debe someter a inventario la herencia y preparar un mundo para habitar (Arendt, 1993).

Con estos elementos conjugados, la formación y el carácter político de todo ser humano, se configura la mirada a la construcción de la subjetividad política. Se tiene al sujeto como expresión de su interacción con el mundo, y se cuentan las formas particulares en las que se expresa esa subjetividad en el modo de organizarse para vivir con los otros.

Sin embargo, es importante anotar que esos procesos de memoria y formación subjetiva no se producen al margen de los conflictos y tensiones por el sentido que constituyen. En el amplio espectro social, los diferentes actores vinculados a los acontecimientos se ven involucrados en luchas y pugnas por la memoria que a la postre inciden en la forma como los sujetos se organizan para vivir juntos.

Con estos elementos, entendemos con Elizabeth Jelin (2002) que un trabajo de investigación sobre la memoria, desde la perspectiva ética y política, comporta por lo menos los siguientes tres aspectos:

Primero, entender las memorias como procesos subjetivos, anclados en experiencias y marcas simbólicas y materiales.

Segundo, reconocer a las memorias como objeto de disputas, conflictos y luchas, lo cual apunta a prestar atención al rol activo y productor de sentido de los participantes en esas luchas, enmarcados en relaciones de poder.

Tercero, "historizar" las memorias, o sea, reconocer que existen cambios históricos en el sentido del pasado, así como en el lugar asignado a las memorias en diferentes sociedades, climas culturales, espacio de luchas políticas e ideológicas (p. 2) (Énfasis en negritas en el original).

Pero, ¿puede analizarse este fenómeno en todo el territorio nacional? Es probable que no. 
En Colombia, la violencia política se ha manifestado en todos los periodos y regiones con variaciones de intensidad, duración y tipos de actores en conflicto. De manera que seguirle la pista a la evolución del fenómeno en toda su extensión puede resultar una tarea demasiado amplia para un solo proyecto.

Por esta razón, para desarrollar investigaciones en este campo, es necesario concentrarse en una región y temporalidad específica en busca de identificar las configuraciones particulares y sus relaciones con la dinámica global ${ }^{2}$.

Una forma de delimitar para el análisis una región y una temporalidad de la violencia política en Colombia puede responder a los fenómenos transitorios de conclusión de la acción mencionados por Hannah Arendt³ y a la necesaria distancia en el tiempo del acontecimiento descrita por Hans Georg Gadamer (2002). Estos teóricos han mencionado la importancia de que los actos cesen para recuperar la memoria de los protagonistas, y que para favorecer la comprensión, en el sentido hermenéutico, es necesaria la distancia en el tiempo, porque de esta forma las construcciones de memoria pueden sedimentarse a través de procesos de conversiones sistemáticas en las formas de darle sentido.

En la actualidad, esas condiciones pueden observarse en regiones como el sur del Casanare, debido a que la conflictividad armada en esa parte del país cesó en el año 2005 y en la actualidad no hay presencia visible de ningún grupo armado al margen de la ley. Esto permite que, bajo la figura de la distancia en el tiempo y el "cese de los actos violentos" en la zona, los sujetos tengan mayor libertad de hacer memoria sobre lo ocurrido. Además, nuevas condiciones socioeconómicas y la presencia del Estado en términos de seguridad e inversión social parecen incubar en esta región alternativas a favor de un orden gubernamental.

Como en todo el territorio colombiano, el departamento de Casanare ha sido escenario de múltiples expresiones de violencia política que, con el tiempo, han permeado la subjetividad de sus pobladores frente al tipo de relaciones que establecen con los Otros. Y como en todo el país, las expresiones de violencia política en el departamento han resultado decisivas para definir los rumbos de vida que se tejen en el seno de la familia, la escuela y las demás instituciones de socialización primaria.

2 Este ha sido el enfoque metodológico de la Comisión Nacional de Reparación y Reconciliación (CNRR).

3 Escribe Hannah Arendt en Sobre la humanidad en tiempos de oscuridad. Reflexiones sobre Lessing (1953, p. 31) "El significado de un acto se revela cuando la acción en sí ha concluido y se ha convertido en una historia susceptible de narración". 
Para pensar en clave de historia reciente, a partir de los años ochenta ${ }^{4}$, en el departamento de Casanare se empezó a configurar una expresión de la violencia por cuenta de diversos actores sociales. Un extenso conflicto entre diferentes grupos armados produjo muerte y desolación entre la población civil y los participantes armados del conflicto en unos niveles que aún no se conocen plenamente. Sin embargo, algunos datos mencionan que entre los años 1986 y 2007 se perpetraron crímenes de lesa humanidad como la desaparición forzada, el desplazamiento y el asesinato de personas por el control territorial. De acuerdo a un informe titulado "Los desaparecidos del Casanare" de Human Rights Data Analisys, en el cual se analizan los patrones de violencia en la región, el número total de desaparecidos para el periodo entre 1986 y 2007 es de 2553 personas (Guzmán, Guberek, Hoover y Ball, 2007).

Sí tenemos en cuenta que por lo irregular de la confrontación no se sabe a ciencia cierta la cantidad de muertos durante esta etapa de violencia, se puede observar con este dato que el drama social es profundo e intenso. Muchas familias quedaron desarticuladas con la muerte o desaparición de sus seres queridos, y otras tuvieron que desplazarse forzosamente para empezar de nuevo en otras regiones. Esto configuró un panorama diverso de víctimas que permanecen silenciadas por las políticas estructurales del Estado en aspectos fundamentales como la educación, debido a que no existe una política clara para que en la escuela se analice la violencia política del país.

\section{Una serie de acontecimientos violentos que merecen ser contados}

En los primeros meses del año del 2004, los participantes de dos grupos paramilitares ${ }^{5}$ se enfrentaron por el control militar del sur del departamento de Casanare en una de las etapas más conflictivas que ha experimentado la región. Durante este tiempo, una serie de enfrentamientos armados se extendieron por todo el sur del Departamento, lo que produjo muertes entre los participantes, pánico y desplazamiento forzado entre la comunidad de las diferentes veredas. Muchos jóvenes que habitan hoy la región estuvieron en medio de los enfrentamientos mientras siendo niños asistían a la escuela y desarrollaban sus actividades habituales.

4 Aunque algunas perspectivas de la construcción de las periodizaciones de la historia reciente, presente, actual y coetánea señalan la década de los sesenta como inicio de esta "parcela" temporal controvertida historiográficamente.

5 El término hace referencia a la organización y funcionamiento de estructuras armadas "paralelas" al ejército regular pero que actúan al margen de la ley. Las estructuras paramilitares suelen manifestar apoyo al Estado o a las fuerzas enquistadas en él (como conocimiento popular pero no oficial). 
Con ello se configuró una base experiencial que ha marcado la forma como entienden y comprenden actualmente el mundo.

Aunque a la fecha ningún documento da una cuenta exacta de las víctimas de estos enfrentamientos, entre la comunidad circulan versiones de cifras de participantes muertos y heridos que han creado una memoria trágica de esos acontecimientos. Refiriéndose al tema en una entrevista reciente, un maestro de la época menciona que:

\begin{abstract}
Alguien me decía hace ocho o quince días que en esta zona hay más de dos mil muertos de uno y otro lado, y que mucha gente había por ahí en los Urales ${ }^{6}$ tapados, abandonados por la guerra. Entonces, si un ejemplo, un historiador dijera hoy, "muestre a ver escribo" [sic], pues eso quedaría para los recónditos análisis del tiempo y hasta bueno recordarla como historia, como recuerdo de una comunidad que sufrió con tantos combates, tanta vida inhumana, que eso sería significativo pero como vivencia mejor olvidar (Testimonio de un profesor de la zona, 2011).
\end{abstract}

En diferentes documentos periodísticos se dice que este conflicto "dejó una cifra astronómica de muertos que hoy la justicia calcula en mil jóvenes" (Así creció el paramilitarismo en los Llanos Orientales, s. f.), esto muestra la falta de consenso en la dimensión estadística de las víctimas de estos enfrentamientos armados. Sin embargo, en lo que sí parece haber consenso es en el carácter dramático de la experiencia en el conjunto de la comunidad por presentarse en los espacios más significativos de su cotidianidad como los caminos, los alrededores de las escuelas, las fincas y los centros poblados.

Finalmente, toda esta confrontación armada cesó con la ocupación y control del territorio de uno de los grupos armados a partir del segundo semestre del año 2004. Después de un año de ocupación y control de la zona, este grupo se desmovilizó completamente en septiembre del año 2005; el ejército y la policía estatal asumieron el control de la zona. Desde entonces, la comunidad ha venido haciendo un tránsito a nuevas formas de relación por cuenta de la dinamización económica que han introducido compañías de exploración petrolera y la adecuación de tierras para cultivos de arroz y palma africana.

Hoy, esos niños que experimentaron toda esa confrontación armada son los jóvenes que acuden a las clases en el colegio de secundaria que se construyó para que continuaran estudiando sin salir de la región; y son ellos los portadores de la memoria de estos hechos de violencia política.

6 El término parece desprenderse de la comparación entre los terrenos accidentados de los montes Urales que dividen a Europa de Asia con los "cantiles" (que a la vez alude a los acantilados) que se configuran en las sabanas inundables del sur de Casanare. 
En consecuencia, las narrativas de los jóvenes de la región sobre los acontecimientos de violencia ocurridos en la región del sur de Casanare, dan cuenta de la forma en que estos hechos alteraron el relato de su experiencia social. Las narraciones sobre estos acontecimientos pueden mostrar los elementos de la subjetividad que se han venido sedimentando a raíz de las expresiones de violencia en la región, y se constituyen en elementos de análisis para la comprensión de las formaciones de la subjetividad en contextos de violencia política.

Con estos elementos, deviene la pregunta por las formaciones de la subjetividad ética y política que se expresan en las memorias sobre la violencia política en la voz de jóvenes escolares del sur del Casanare, y el propósito de interpretar las formaciones de la subjetividad ética y política de un grupo de jóvenes del sur del departamento de Casanare, a partir de la memoria narrativa de los acontecimientos violentos que tuvieron lugar en la zona durante el año 2003 y el primer semestre del año 2004.

\title{
Marcos sociales de la memoria
}

Como ya se dijo, la memoria siempre es sobre algo, un acontecimiento, un evento significativo, algo que marca la experiencia, pero a este principio fenomenológico también se puede agregar otro igualmente importante: la memoria se ancla a un espacio de relaciones entre personas.

Si bien la memoria es una construcción personal y se constituye en el ámbito de la subjetividad, también es cierto que la interrelación de los sujetos en un espacio físico, una historia común, un sistema de organización política y un marco cultural específico determina el sentido de las memorias individuales.

\begin{abstract}
El individuo evoca sus recuerdos apoyándose en los marcos de la memoria. En otras palabras, los diversos grupos integrantes de la sociedad son capaces en cada momento de reconstruir su pasado [...] ciertamente, existen muchos hechos, bastantes detalles de los hechos, que el individuo olvidaría, si los otros no los conservan para él (Halbwachs, 2004, p. 336).
\end{abstract}

Esta referencia de Halbwachs se completa en el proyecto con la interpretación que hacemos de los marcos sociales de la memoria como entidades más o menos estables que fijan determinados sentidos sobre el pasado. De acuerdo con este autor, los marcos sociales de la memoria se configuran a través de instituciones sociales como la familia, la religión, la clase social, las tradiciones porque dada su estabilidad temporal logran fijar interpretaciones sobre el pasado y permiten realizar reconstrucciones colectivas de ciertos acontecimientos que marcan cambios importantes en la dinámica social. 
Sin embargo, no se trata de una descripción escueta y estadística de las interacciones sociales ligadas a acontecimientos fundadores y dinámicas de estabilización. El propósito de esta investigación es seguir la veta de las formaciones subjetivas incluso en los intersticios sedimentados de la historia. La descripción que sigue pretende construir una serie de anclajes para conectar aspectos de la memoria narrativa de los jóvenes que sirven a la tarea de comprender las formaciones de la subjetividad ética y política.

Para este ejercicio, se ha delimitado un área geográfica que se ha denominado el sur del Casanare, de acuerdo a un fenómeno de presencia y enfrentamiento de grupos armados que configuran una memoria de un hecho violento de carácter político que, se cree, incide en la formación de la subjetividad ética y política de jóvenes de esa región. Por tanto, la delimitación geográfica para este ejercicio corresponde en gran medida al espacio de esos enfrentamientos y la historia del poblamiento se circunscribe a la historia macro del departamento, pero se concentra en los aspectos particulares del área establecida.

\section{Justificaciones}

El trabajo de investigación se inscribe en el campo de la educación como una forma de entender los fines y el sentido de los procesos formativos para el contexto de nuestro país, porque como dice el profesor Armando Zambrano (2005), "en cuanto está dirigida a la especie humana, la educación expresa unas finalidades, unos actos y unos medios [agregando que] la conjugación equilibrada de estos está vinculada directamente con la idea del Hombre que la sociedad haya construido" (p. 105). Es decir, toda sociedad construye un ideal de ser humano y prepara el futuro a través de consecutivas acciones formativas. Para este efecto, se prevén unos espacios, tiempos y prácticas que se orientan por unos fines que permiten materializar las aspiraciones de ese conjunto social en particular.

Para este proyecto, se asume y comparte el objeto de la Ley 115 de 1994 (Ley General de Educación de Colombia), la cual establece que "la educación es un proceso de formación permanente, personal, cultural y social que se fundamenta en una concepción integral de la persona humana, de su dignidad, de sus derechos y de sus deberes". Y se retoman dos de los fines de la educación para justificar el desarrollo del proyecto.

De acuerdo al capítulo 5, numerales 2 y 3, la educación debe promover:

» La formación en el respeto a la vida y a los demás derechos humanos, a la paz, a los principios democráticos, de convivencia, pluralismo, justicia, solidaridad y equidad, así como en el ejercicio de la tolerancia y de la libertad. 
» La formación para facilitar la participación de todos en las decisiones que los afectan en la vida económica, política, administrativa y cultural de la Nación.

Con esta selección de objeto y fines de la educación, el autor se suma a lo dicho por el profesor Zambrano (2005) cuando menciona que "educar es pensar al hombre desde su ser político, su trascendencia y la forma en que estas deben ser asumidas desde el ideal del hombre que la sociedad se forja" (p. 112). De esta forma, la educación colombiana debe promover la participación efectiva de los sujetos en las decisiones que los afectan, y sobre todo, debe generar condiciones para que se garantice la vida y el derecho a pensar de forma diferente.

Para este efecto, es indispensable que los educadores puedan abordar la violencia en Colombia desde una mirada comprensiva, porque como dice Elizabeth Jelin "el espacio escolar es clave para la trasmisión de saberes específicos, pero también se espera que lo sea para la trasmisión de valores y reglas sociales" (Jelin y Lorenz, 2004, p. 2). Frente a esta posibilidad, el análisis de la violencia en Colombia puede relacionarse con la necesidad de construir apuestas formativas que intenten comprometer a los sujetos con la vida y los derechos de los Otros.

Con estos elementos, el proyecto se propone:

》 Construir un enfoque teórico y metodológico que permita abordar la comprensión de las formaciones de la subjetividad en contextos de violencia política.

»Destacar las formaciones de la subjetividad ética y política que se expresan en las narraciones de los jóvenes del sur de Casanare.

» Proyectar acciones educativas relacionadas con los resultados del proyecto de investigación.

\section{Desarrollo metodológico}

Para el desarrollo metodológico, se tomó como referente la conceptualización que hace Paul Ricoeur sobre la memoria y la narrativa como base para la constitución y formación de la subjetividad. No obstante, estos elementos se ampliaron con los principios de la hermenéutica y las categorías analíticas que persigue el objeto del proyecto: memoria narrativa, violencia política y formación de la subjetividad.

En particular, esta investigación se entiende como el estudio de un caso a través del modo de expresión narrativo en busca de los elementos singulares que configuran la memoria de un conjunto de hechos de violencia política, que se considera, inciden en la formación de la subjetividad de un grupo de jóvenes del sur del Casanare. 
Para la recolección de los datos se desarrollaron dos tipos de actividades: talleres de activación de la memoria colectiva y entrevistas semiestructuradas. La primera actividad se realizó con un colectivo amplio de 75 jóvenes que participaron del ejercicio de investigación con base en una reconstrucción de los hechos significativos en su conjunto social apoyado en una representación de los lugares y contextos de los acontecimientos.

La segunda actividad, las entrevistas semiestructuradas, se basó en tres preguntas generales: ¿De dónde vienen usted y su familia? ¿Cuál ha sido el evento más significativo de su historia de vida? ¿Cuáles son sus proyectos de futuro? En medio de las respuestas y a través del diálogo aparecieron otras preguntas de acuerdo a los giros y las intrigas propios del programa narrativo de cada sujeto.

Para el caso de este proyecto, se obtuvieron relatos de un grupo de jóvenes que comparten un rango de edad entre los 15 y 19 años. Dentro de este grupo se cruzaron los relatos de mujeres y hombres, hijos de los dueños de las fincas e hijos de habitantes de los centros poblados del sur de Casanare, con el fin de construir una narrativa con fuentes diferentes que pertenecen a un grupo social con una historia común.

Para analizar la información se buscó comprender significativamente los aspectos relevantes de las narrativas, situándolas en un contexto que sirve de base para que tomen un sentido más amplio. Al respecto, se atendieron los siguientes tres principios teóricos y metodológicos:

» Comprender la memoria como relato para develar su sentido.

» Enfrentar la explicación del relato con el ser en el mundo del sujeto para construir un relato nuevo.

» Hacer una lectura experiencial de la formación de la subjetividad ética y política en contextos de violencia, destacando cuáles son las interacciones entre el mundo social y el sujeto que narra.

Para este efecto, se tuvo en cuenta la perspectiva básica de análisis estructural del relato que sugiere Roland Barthes (1977), los aspectos de la tradición, la cultura y la historia que constituyen el mundo social tanto de los sujetos como del investigador, y las categorías analíticas de memoria narrativa, violencia política y formación de la subjetividad ética y política. De esta forma, se trata de dar sentido al concepto de arco hermenéutico de Paul Ricoeur, cuando menciona que la explicación es la base de la comprensión, y que el mundo de la vida es el primer y último donante de sentido de la experiencia.

De esta forma, el modelo para el análisis quedó formalizado bajo las siguientes acciones e intenciones: 
Los relatos de los jóvenes son asumidos como comprensiones de su experiencia de vida.

» El investigador busca interpretar las formaciones de la subjetividad ética y política que subyace a la construcción narrativa. Para este efecto, compone una intención reflexiva y la materializa en categorías analíticas básicas, construyendo un horizonte histórico y cultural del ser en el mundo de los jóvenes a través de la variación de escalas del tiempo histórico.

» Por último, establece un procedimiento para analizar la estructura del relato, para tratar de encadenar los demás aspectos de la comprensión.

» Para operativizar el análisis de las narraciones se usa una ficha analítica (véase la tabla 1).

Tabla 1. Ficha para el análisis de los relatos

\begin{tabular}{|c|c|}
\hline Categorías analíticas & $\begin{array}{l}\text { Convenciones para el análisis estructural } \\
\text { del relato }\end{array}$ \\
\hline $\begin{array}{l}\text { Memoria narrativa: expresión de la experiencia } \\
\text { del ser en el mundo } \\
\text { Violencia política: acontecimientos que con- } \\
\text { figuran tramas narrativas que inciden en las } \\
\text { formaciones de la subjetividad ética y política } \\
\text { Formación de la subjetividad ética y política: } \\
\text { sedimentos de la experiencia del ser en el } \\
\text { mundo que configuran formas de entender y } \\
\text { relacionarse con los Otros }\end{array}$ & $\begin{array}{l}\text { Secuencias narrativas } \\
\text { Funciones distribucionales } \\
\text { Funciones cardinales } \\
\text { Catálisis } \\
\text { Funciones integradoras } \\
\text { Indicios } \\
\text { Indicios informantes } \\
\text { Actantes }\end{array}$ \\
\hline \multicolumn{2}{|c|}{ Variación de escalas micro- y macrohistóricas } \\
\hline Cuerpo del relato & Interpretación \\
\hline $\begin{array}{l}\text { ¿Cómo se miran las formaciones de la sub- } \\
\text { jetividad ética y política en las memorias de } \\
\text { la violencia política de los jóvenes del sur de } \\
\text { Casanare? }\end{array}$ & $\begin{array}{l}\text { ¿Qué aspectos se observarán para interpretar } \\
\text { las formaciones de la subjetividad ética y polí- } \\
\text { tica de los jóvenes del sur del Casanare? }\end{array}$ \\
\hline $\begin{array}{l}\text { Identificando la configuración de la trama } \\
\text { narrativa del relato }\end{array}$ & $\begin{array}{l}\text { Las "voces" que participan en la formación de } \\
\text { la subjetividad }\end{array}$ \\
\hline $\begin{array}{l}\text { A través de la variación de escalas micro- y } \\
\text { macrohistóricas que permiten vincular aspec- } \\
\text { tos especíicos del relato con acontecimientos } \\
\text { de violencia política y cambios sociales }\end{array}$ & $\begin{array}{l}\text { El tipo de interacciones sociales que producen } \\
\text { determinadas formaciones subjetivas }\end{array}$ \\
\hline $\begin{array}{l}\text { Contrastando el sentido de los relatos con } \\
\text { las categorías analíticas del marco teórico: } \\
\text { memoria narrativa, violencia política, formación } \\
\text { y subjetividad ética y política }\end{array}$ & $\begin{array}{l}\text { La manera como se hibridan aspectos de la } \\
\text { cultura y la tradición con las experiencias de } \\
\text { violencia política para configurar las formacio- } \\
\text { nes subjetivas }\end{array}$ \\
\hline
\end{tabular}

Fuente: elaboración propia. 


\section{Formaciones de la subjetividad ética y política en contextos de violencia}

En los ejercicios de activación colectiva de la memoria, los jóvenes fueron desarrollando uno a uno los relatos de violencia política de la que fueron testigos y víctimas. Algunos se mostraron tímidos y precavidos, otros desarrollaron ampliamente una memoria de lo ocurrido, pero en general todo el grupo se refirió a los acontecimientos violentos de los años 2003 y 2004.

En estas narraciones aparecieron aspectos propios de las subjetividades de los jóvenes: algunos bajaban la voz cuando se referían a los grupos armados o a situaciones de muerte, disparos y episodios de estrés. Otros, distorsionaron algunas palabras relacionadas con los grupos armados o a situaciones de muerte, y otros parecían inseguros al hablar de los hechos del pasado que se relacionaban con acontecimientos de violencia política.

No obstante estos aspectos subjetivos, en sus relatos también aparecieron aspectos comunes y metáforas particulares que sirven de horizonte a los relatos.

Por ejemplo, una escena vivida por los jóvenes y sus familias, referida al transporte de los cadáveres del conflicto en plataformas haladas por un tractor, llamadas zorras, representa una imagen que persiste en la memoria de la mayoría de los jóvenes.

(H-19-5): -A mí nunca se me olvida cuando pasaban esas zorradas de muertos, pues uno no estaba acostumbrado a ver tantos muertos, arrumes de gente muerta que pasaban en esas zorras. Yo los veía pasar sin brazos, sin piernas, otros con la cabeza rajada algunos solo se le veía el "croquis" de la cabeza porque por dentro no tenían los sesos, pasaban esa gente por el pueblo; eso es verraco.

(M-18-6): - Por ahí dejaron hartos muertos, entonces los recogían, los echaban en las zorras y se lo llevaban, y pues yo estaba estudiando y me tocó salirme por todo eso.

La escena pública de cadáveres destrozados parece ser un elemento común para referirse al conflicto armado que se vivió en la zona. Cuando cada uno de los jóvenes relata su experiencia, se pueden identificar tramas particulares y diferenciadas de cada uno, pero mientras avanza el programa narrativo aparecen estas referencias comunes que sirven de anclaje de verificación de la realidad histórica que los enmarca.

En términos narrativos, esta referencia actúa como un indicio de la atmósfera de guerra y degradación que se experimentaba en la región por esos días. 


\section{El valor de enfrentar la adversidad}

Otro aspecto común en las narraciones aparece como el valor de agentes de la comunidad para enfrentar situaciones de gran peligro en medio de la confrontación armada. Unirse, dar la cara y responder a los cuestionamientos de los grupos armados, son narrados como actos de valentía que se anudan al relato épico de los acontecimientos:

Esta convicción de que solo puede ser libre quien esté dispuesto a arriesgar su vida jamás ha desaparecido del todo de nuestra conciencia; y lo mismo hay que decir del vínculo de lo político con el peligro y el atrevimiento en general. La valentía es la primera de todas las virtudes políticas y todavía hoy forma parte de las pocas virtudes cardinales de la política, ya que solo podemos acceder al mundo público común a todos nosotros, que es el espacio propiamente político, si nos alejamos de nuestra existencia privada y de pertenencia a la familia a la que nuestra vida está unida (Arendt, 1997, p. 65).

La idea de libertad asociada a la valentía es una referencia para entender que la acción política deviene de un riesgo que se asume por las convicciones más enraizadas en la subjetividad y en el horizonte de una vida buena en instituciones justas. A la vez, esta idea y necesidad de ser valiente y enfrentar la adversidad puede entenderse como una máxima cultural del ser llanero, la cual se ha configurado históricamente a través del proceso de colonización del territorio.

En la narrativa de los jóvenes, aparecen con frecuencia estas valoraciones como elementos organizadores de los relatos.

(H-17-1): -Cuando al segundo día vinimos y mandaron llamar a mi papá porque supuestamente él era paraco ${ }^{7}$, lo mandaron a sentar ahí porque si no llegaba lo mataban, se fueron con mi mamá los dos y un hermano. Fueron allá, enfrentaron todo y revisaron la casa, no había nada, lo de arriba abajo y lo de abajo arriba [...].

(H-17-3): Se acababan de llevar un hermano mío, lo engañaron, pero a lo último lo soltaron, porque llegaron ahí, llegó un primo para que los llevara a un lado. Mi papá lo que hizo fue irse para donde ellos estaban, solo; a pedirles que lo soltaran.

(H-17-3): -Estaba un Buitrago que le decían el pavo, era uno de los más peligrosos de esa gente, andaba buscando muchachos para llevarse, estaba solo entonces no encontraron nada, por ahí arriaban madres ${ }^{8}$, nosotros por ahí metidos en una casa escuchando todo, cuando salieron pasó el susto. La gente al otro día volvía, volvió una que otra gente, otros no volvieron, los muchachos que tenían cuerpo de hombre se 
quedaban al otro lado del río, y cuando esa gente pasaba al otro lado del río tocaba traerlos pa' este lado. Entonces se iban pa' Carupana, para Tunupe, se la pasaban así de un lado para otro, y así se la pasaba también la gente escapando.

En esta última referencia, se destaca que muchos sujetos osados y atrevidos constituyeron un espacio público para sus acciones al arriesgar su vida para proteger a otros del reclutamiento ilegal y la persecución. Es ahí donde aparece el valor político de estas acciones: que algunos sujetos arriesgaron su vida por sus convicciones y que se ubicaron en el espacio público como seres libres con sus iguales.

\section{Lo mítico y religioso en las formaciones de la subjetividad}

De otro modo, en las narraciones aparecen conjugadas las construcciones míticas y religiosas en el marco de experiencias traumáticas de guerra que configuran sentidos éticos y políticos particulares. Por ejemplo, la interiorización del código de conducta moral cristiana le funciona a buena parte de la población para valorar el comportamiento de los Otros. En una circunstancia donde brilla por su ausencia el marco jurídico del Estado, la autoridad de Dios y el dogma cristiano se fortalecen como la medida de justicia por excelencia, y así, los castigos y las recompensas por las acciones se manifiestan en aspectos como la salud y la enfermedad de los sujetos según cómo dañen o ayuden a los Otros.

(H-17-3): -Pues yo he aprendido que uno no debe dejarse llevar por malas amistades, ni nada, uno debe pensar con cabeza fría y con corazón, y pensar que todos los humanos tenemos derecho a vivir, para mí, como yo nunca he sido malo ni nada, tampoco vicioso, no me gusta nada de eso, me gusta ayudar a las personas y que me ayuden así como yo los ayudo, así no pienso en nada malo, eso le hace ver las cosas a uno con claridad, de otra forma, lo hace pensar que lo malo uno no lo debe hacer, uno debe guiarse por lo bueno y no por lo malo; yo nunca he estado hospitalizado, a mí no me han hospitalizado, mi Diosito me cuida.

En otros casos, las formaciones de la subjetividad aparecen como expresiones de la memoria enferma e impedida a causa de experiencias de violencia que desbordan la capacidad del sujeto para elaborarlas simbólicamente.

(H-19-4): -Cuando eso mataban gente a diario y todo y gentes que tenían pactos con el diablo, entonces esas almas quedaban en pena y yo tenía como doce, quince años, entonces un alma se encarnó en mí y casi me lleva, o sea me sacó de la finca, yo corriendo de noche, o sea yo no era consciente de lo que hacía. 
Este fenómeno puede Ilegar a analizarse de forma individual, a nivel psicológico, pero también encuentra su correlato en la fragmentación del lazo social que genera la violencia política: en "momentos de oscuridad", cuando la violencia debilita los vínculos de solidaridad, ocurre lo que Daniel Pécaut (2002) Ilama el repliegue individualista, lo cual conduce a que cada quien se las arregle por sí mismo sin el necesario apoyo del colectivo que enmarca su identidad. De manera que cuando los sujetos son desbordados por experiencias traumáticas de guerra, muchas veces deben enfrentar esa circunstancia sin el apoyo del tejido colectivo que los incluye histórica y culturalmente.

\section{La subjetividad militarista}

Así mismo, en el desarrollo de la investigación se pudo identificar un tipo de formación ética y política relacionada con las prácticas militares que atravesaron gran parte de la experiencia de uno de los sujetos jóvenes que participó en el ejercicio. Como se ha mencionado, en la región del sur del Casanare operaron grupos paramilitares durante un periodo prolongado -que en ocasiones cubre toda la experiencia de vida de algunos de ellos- y este aspecto ha incidido en la forma como algunos jóvenes proyectan su futuro.

Cuando el investigador le preguntó a uno de ellos, “¿Que está pensando hacer después de que salga del colegio?" el joven contestó: "Lo primero, entrar al ejército es lo que esperaba desde hace ocho, nueve años, desde que estaba esa gente soñaba con prestar servicio en el ejército" $(\mathrm{H}-18-2)$.

Como se observa, las proyecciones de futuro que se muestran en este fragmento del relato se relacionan con fuerza con la subjetivación militarista que atraviesa la experiencia del ser en el mundo del narrador. Desde niño viene recibiendo la marcada influencia de participantes armados de diferentes filiaciones, y este aspecto ha configurado una manera de situarse frente a los demás.

Sus apuestas por el futuro se articulan con el deber de mantener la paz y conjurar la violencia que se ha experimentado en la región por muchos años bajo la premisa de que: "si no hubieran los militares mejor dicho no viviría uno así como está ahorita en paz ¿sí?, donde no hubieran ellos mejor dicho los que mandaban eran otros y nunca debemos dejar acabar eso" (H-18-2).

\section{A modo de conclusión}

El concepto de formación que se desarrolla en este trabajo desborda los límites de la escuela y vincula el amplio marco significante que representa 
el pasado común, la cultura y las tradiciones que enmarcan los procesos identitarios de un determinado colectivo social.

Con estos elementos, puede pensarse en proyectos educativos que vinculen las múltiples voces que participan en la formación de las subjetividades éticas y políticas de los jóvenes. Al respecto, y en el caso de este proyecto, hablamos de la voz de todos los agentes comunitarios: habitantes de los centros poblados, propietarios de las fincas, trabajadores, madres y padres de familia, agentes de las instituciones del Estado, pero también de las voces que vienen del pasado lejano y que se expresan en la tradición y la cultura que enmarca la identidad de los sujetos; de las otras voces que se vinculan al mundo de la vida a través de medios como internet y la televisión y que conectan voces tan disimiles como la de participantes armados con distintos intereses, políticos, periodistas, activistas de ONG internacionales, entre otros.

Para este efecto, pueden atenderse las sugerencias teóricas y metodológicas que se han desarrollado en este trabajo, tales como:

» Identificar esas múltiples voces organizadas como relatos y asumirlas como textos $u$ otras expresiones del lenguaje.

» Analizar el sentido de cada uno de estos relatos como mundos que se independizan del dador del discurso, con base en los elementos para un análisis estructural del relato y en el horizonte histórico y cultural que sirve de contexto para la lectura.

» Poner de presente esos múltiples sentidos para comprender de qué manera inciden en las formaciones de la subjetividad ética y política de todos los agentes comunitarios.

» Configurar acciones con base en esas comprensiones de cara a la idea de futuro que subyace, es decir, de cara a la idea de sujeto educado que se desprenda de esos ejercicios de comprensión

» En particular, estas sugerencias teóricas y metodológicas pueden materializarse en objetivos educativos como los siguientes:

\section{Cuestionar las múltiples versiones del pasado reciente para promover la toma de postura ética y política de todos los agentes}

Como se ha dicho, frente al pasado se asiste a una pugna por el sentido que se materializa en memorias diversas sobre los mismos acontecimientos, porque cada conjunto de actores sociales evidencia su postura ética y política al narrar su experiencia. Por esa razón, es fundamental que se identifiquen esas memorias y se establezcan los intereses de sus agentes y su lugar en la trama social amplia. 
En esta tarea, es importante recordar que frente a esta selección y discusión, las víctimas deben cobrar un protagonismo que anude la búsqueda a su reivindicación y al anhelo de justicia.

\section{Apoyo psicosocial a las víctimas de la violencia}

Es importante que el conjunto de instituciones del Estado, la sociedad civil y las ONG nacionales e internacionales se comprometan con el apoyo psicosocial a las víctimas de la violencia del sur de Casanare a través del apoyo terapéutico, pero sobre todo con el desarrollo de acciones dirigidas a reconstruir el tejido social de la comunidad.

En la actualidad, muchas de esas víctimas continúan sobrellevando la carga de dolorosas experiencias de violencia que hacen difícil aprender del pasado o pasar la página para ver de frente el futuro.

Por cerrar este aparte y proyectar, tal vez, la más importante de las alternativas educativas, retomamos la siguiente pregunta de Walter Benjamín (2010): ¿Es posible una regulación no violenta de los conflictos? A lo cual responde:

El acuerdo no violento surge doquiera que la cultura de los sentimientos pone a disposición de los hombres medios puros de entendimiento. A los medios legales e ilegales de toda índole, que son siempre violentos, es lícito por lo tanto oponer, como medios puros, los medios no violentos. Delicadeza, simpatía, amor por la paz, confianza y todo lo que podría añadir son su fundamento subjetivo (p. 102).

Como se ha visto, pueden ser muchas las consideraciones sobre el uso o el tratamiento educativo de la memoria de la violencia política en Colombia, y todas dependen del marco específico de comprensión. En este trabajo, se han explorado algunos marcos teóricos y conceptuales que eventualmente pueden alimentar ideas como la de una pedagogía de la memoria, pero como se ha visto, esa configuración siempre dependerá de la postura de cada sujeto: de su lugar en el mundo, de su memoria, su forma de narrar y ser narrado. 


\section{Referencias bibliográficas}

Amaya, P. (Director del proyecto) (2000). Colombia, un país por construir. Bogotá: Universidad Nacional.

Arendt, H. (1993). La condición humana [introducción de Manuel Cruz] (Ramón Gil Novales, trad.). Barcelona: Paidós.

Arendt, H. (1997). ¿Qué es la política? [introducción de Fina Birulés] (Rosa Sala Carbó, trad.). Barcelona: Paidós.

Arendt, H. (2004). Los orígenes del totalitarismo (Guillermo Solana, trad.) 4. ${ }^{\mathrm{a}}$ ed. México: Taurus.

Así creció el paramilitarismo en los Llanos Orientales. (s. f.). Verdad abierta. Recuperado de: http://www.verdadabierta.com/victimarios/3056--asi-crecio-el-paramilitarismo-en-los-Ilanos-orientales.

Barthes, R. (1977). Introducción al análisis estructural del relato. En S. Niccolini (comp.) (B. Doriots, trad.). El análisis estructural. Buenos Aires: Centro Editor de América Latina.

Burke, P. (comp.). (2003). Formas de hacer historia (J. L. Gil Aristu y F. M. Arribas, trad., 2. ${ }^{\text {a }}$ ed.) Madrid, España: Alianza.

Castillejo, A. C. (2000). Poética de lo otro: para una antropología de la guerra, la soledad y el exilio interno en Colombia. Bogotá: Ministerio de cultura, Instituto Colombiano de Antropología e Historia, Colciencias.

Deas, M. (1995). Canjes violentos: reflexiones sobre la violencia en Colombia. En Dos ensayos especulativos sobre la violencia en Colombia. Fonade-DNP

Gadamer, H. G. (2002). Verdad y método: fundamentos de una hermenéutica filosófica (A. Agud Aparicio y R. de Agapito, trad.). Salamanca: Sígueme.

Guzmán, D.; Guberek, T.; Hoover, A. y Ball, P. (2007). Los desaparecidos de Casanare, p.1. Recuperado de: http://www.hrdag.org/resources/ publications/casanare-missing-report-final-ES.pdf

Halbwachs, M. (2004). Los marcos sociales de la memoria [posfacio de Gérard Namer] (M. A. Baeza y M. Mujica, trad.). Barcelona: Anthropos, Universidad de Concepción, Facultad de Ciencias Sociales.

Heidegger, M. (1951). El ser y el tiempo (J. Gaos, trad.). México: Fondo de Cultura Económica.

Jelin, E. (2002) Los trabajos de la memoria. Madrid, España: Siglo xxı de España Editores.

Jelin, E. \& Lorenz F. G. (comps.). (2004). Educación y memoria: la escuela elabora el pasado. Madrid: Siglo xxı de España Editores, SSRC.

Leví, P. (1989). Los hundidos y los salvados(P. Gómez Bedate, trad.). Barcelona: Muchnik. 
Ley General de Educación para Colombia. Ley 115 de 1994. Bogotá, Colombia.

Moya, C. (1996). El sujeto enunciado. En M. Cruz (comp.). Tiempo de subjetividad. Barcelona: Paidós Basic.

Nietzsche, F. (2005). Sobre verdad y mentira en sentido extramoral. Madrid: Tecnos.

Pécaut, D. (2000). Las configuraciones del espacio, del tiempo y de la subjetividad en un contexto de terror. Revista Colombiana de Antropología, 35, 8-35.

Todorov, T. (2012). Los usos de la memoria. Tema abordado en la conferencia dada por el autor en el IDEH-PUCP en noviembre de 2012.

Ricouer, P. (1995). Tiempo y narración I. Configuración del tiempo en el relato histórico (A. Neira, trad.). México: Siglo Veintiuno.

Ricouer, P. (1997). Autobiografía intelectual. (P. Wilson, trad.). Buenos Aires: Nueva Visión.

Ricouer, P. (1999). Historia y narratividad [introducción de Ángel Gabilondo y Gabriel Aranzueque]. Barcelona: Paidós, ICE de la Universidad Autónoma de Barcelona.

Ricouer, P. (2003). Sí mismo como otro (A. Neira Calvo, trad.) [con la colaboración de María Cristina Alas deTolivar] (2. ${ }^{\text {a }}$ ed.). México: Siglo Veintiuno.

Ricouer, P. (2004). La memoria, la historia y el olvido (A. Neira, trad.). México: Fondo Cultura Económica.

Vargas, G. (comp.). (2007). Formación y subjetividad/. Bogotá: Universidad Pedagógica Nacional.

Zambrano, L. A. (2005). Didáctica, pedagogía y saber. Bogotá: Colombia. Cooperativa Editorial Magisterio.

Zemelman, H. (1996) Problemas antropológicos y utópicos del conocimiento. México: El Colegio de México. 